\title{
Graduate Skills in Business Learning
}

\author{
Tori $\mathrm{Vu}$ (Corresponding author) \\ Faculty of Business and Economics, Macquarie University \\ Sydney, NSW 2109, Australia
}

Tel: 61-2-9850-4753 E-mail: tori.vu@mq.edu.au

Brendan Rigby

Faculty of Business and Economics, Macquarie University

Sydney, NSW 2109, Australia

E-mail: Brendan.rigby@gmail.com

Leigh N. Wood

Faculty of Business and Economics, Macquarie University

Sydney, NSW 2109, Australia

Tel: 61-2-9850-4756 E-mail: leigh.wood@mq.edu.au

Anne Daly

Faculty of Business and Government, University of Canberra

Canberra, ACT 2601, Australia

Tel: 61-2-6201-2717 E-mail: Anne.daly@canberra.edu.au

Received: February 6, $2011 \quad$ Accepted: February 23, $2011 \quad$ doi:10.5539/ass.v7n4p2

Support for this project has been provided by the Australian Learning and Teaching Council, an initiative of the Australian Government Department of Education, Employment and Workplace Relations. The views expressed in this paper do not necessarily reflect the views of the Australian Learning and Teaching Council Ltd.

\begin{abstract}
This article presents the background to a general increase in interest in developing the graduate skills of undergraduates in business in Australian universities. The change reflects the call from industry for greater emphasis on these skills; changes in the existing skills of students commencing a business education; and in the perceived role of universities in developing their students' capacities. The aim of our project, "Embedding the development and grading of generic skills across the business curriculum" (EDGGS), was to develop new ways of successfully embedding these skills in the curriculum. This article outlines the research methodology and presents our project outcomes. The project has made a significant contribution to the development of readily accessible material for the embedding of generic skills in the business curriculum, as discussed in this and the other articles in this Issue.
\end{abstract}

Keywords: Graduate skills, Generic skills, Business education, Action research

\section{Introduction}

Our project - the "Graduate Skills project" - is a practical response to concerns about graduates' preparedness for work, both in Australia and globally (Vu, Rigby, \& Mather, 2011). We have developed and evaluated learning and teaching resources and strategies for universities to enhance the graduate skills of undergraduates; and, further, to embed these skills in business programs of universities across Australia. We chose to concentrate on a subset of graduate skills, namely teamwork, critical thinking, ethical practice and sustainability. The first three 
were skills identified as being essential for business graduates in a scoping study conducted by the Australian Business Deans Council (ABDC) (Freeman et al., 2008). The Business Industry and Higher Education Collaboration Council (BIHECC) report from 2007 also identifies these skills as important, and BIHECC maintains that, "More than ever we need professionals who are responsive to economic, social, cultural, technical and environmental change and can work flexibly and intelligently across business contexts." (BIHECC, 2007, p. 1) From the perspective of acknowledging the importance of environmental issues, and considering the expanding place of sustainability in corporate, public and academic discourse, we added sustainability to the skills of teamwork, critical thinking and ethical practice; sustainability also features in the graduate attribute statements of many universities. These skills are complex, and the existing literature does not display a shared understanding of their meaning or how to develop them. There was clearly a need to address the learning and assessment of these graduate skills in a discipline-specific context.

Australia has 38 universities which offer business undergraduate programs. There are around 173000 full-time-equivalent students studying business-related degrees in Australia. The Graduate Skills project was a cross-institutional research grant involving seven universities in six Australian states (Macquarie University, University of Canberra, Australian Catholic University, Edith Cowan University, LaTrobe University, University of Southern Queensland and University of Tasmania). The Australian Learning and Teaching Council (ALTC), which finances projects in order to support learning and teaching at Australian universities, provided funding for this project between 2008 and 2010. Our project was initiated by the ABDC Teaching and Learning (T\&L) Network, which represents all Associate Deans who have responsibility for learning and teaching in business faculties.

\section{Background}

\subsection{What are graduate skills?}

The move to incorporate generic or "soft" skills explicitly in undergraduate curricula is fairly recent. It has been so widely accepted, however, that by 2010 all universities in Australia had statements about what their graduates will be able to do. There are significant differences in the statements: some promise skills, others attributes, some capabilities, and some are developing dispositions. The literature is equally mixed as to terminology and indeed even in this Issue the authors move between generic skills, graduate skills, graduate attributes and dispositions. For our project we use the term "graduate skills" to incorporate all these diverse terms. In the next article (Wood, Thomas, \& Rigby) we show how we have developed and tested rubrics to measure the achievement of these graduate skills. We divided the achievement into conceptual, procedural and professional knowledge, and have defined five levels of achievement. In our view, graduate skills should be measurable and tested in discipline-specific contexts at university - statements such as "developing lifelong learning skills" become difficult to measure unless you are following graduates as they move into professional work.

\subsection{Industry perspectives in Australia}

The ABDC conducted a scoping study of key industry, professional and academic stakeholders, "Business as usual? A collaborative and inclusive investigation of the existing resources, strengths, gaps and challenges to be addressed for sustainability in teaching and learning in Australian university business faculties" (Freeman et al., 2008). The study identifies the development of graduate skills in higher education as a salient theme. However, "there was little agreement about the degree to which generic skills were important ... whose responsibility they were to teach ... or how they should be assessed." (p. 23) On the other hand, "there was general agreement that graduate skills were important for graduates and that students were not demonstrating generic skill development from their university studies as well as they might be." (pp. 22-3)

In addition to the ABDC scoping study (Freeman et al., 2008), a report by BIHECC (2007) highlights the development and promotion of critical thinking, teamwork, global sustainability, ethical practice and lifelong learning as expected outcomes of business education. There is strong research-based evidence that professional employability requires graduates to be able to demonstrate their achievement of graduate attributes (Treleaven \& Voola, 2008; Hoban et al., 2004; Kember \& Leung, 2005); for instance, "In the Australian context, employers have been so dissatisfied with the skills and competencies of graduates that the Australian government considered for a time linking graduate skills testing with federal funding." (Treleaven \& Voola, 2008, p. 161) The Australian Chamber of Commerce and Industry and the Business Council of Australia (BCA) both assert that many university graduates do not have appropriate "soft skills", including those of teamwork, communication, problem solving, lifelong learning, creativity and inter-cultural competence. A recent BCA report (2006, cited in Thompson et al., 2008) affirms that employers continue to be dissatisfied with the skill level of university graduates. It also identified critical thinking, teamwork and ethical practice as key graduate 
skills that need to be addressed in higher education; indeed, "universities should be concerned about claims of a skills deficit of their graduates" (Star \& Hammer, 2007, p. 240).

In accounting practice, the Australian Society of Certified Practising Accountants and the Institute of Chartered Accountants in Australia (1997) released a joint accreditation statement in 1997 urging tertiary educational institutions to teach explicitly a range of graduate skills in their accredited programs. The National Centre for Vocational Education Research (2009, p. 2) relates the importance of generic skills to employability and describes them as "service-oriented" and, according to their report, students with the requisite graduate skills will have a "comparative advantage in the labour market". They also mention that graduate skills enable students to be reflective and self-directed learners, active citizens and community participants: "Generic skills feature prominently in this body of literature as fundamental to developing progressive communities." (NCVER, 2009, p. 2) The Kirby Report (2000, cited in Hager, Holland, \& Beckett, 2002) highlights the shift to a knowledge-based economy, and the demands and expectations of employers for graduates who are able to successfully participate and contribute to this economy. A report funded by the Department of Education, Training and Youth Affairs (2000, cited in Hager, Holland, \& Beckett, 2002), "Employer satisfaction with generic skills", reports that the overall performance of graduates was only "reasonable". Of particular importance was the perceived lack of graduate capacity for independent and critical thinking. The report notes that, "this skill is of great importance to employers, and seems to be the skill that most sets apart successful from unsuccessful applicants: in other words, employers value this skill, and can find it but it is rare." (p. viii, cited in Hager, Holland, \& Beckett, 2002, p. 4)

\subsection{The shifting role of universities}

Graduates - in the business environment or otherwise - face uncertain employment prospects in the 21 st century, a situation aggravated by the recent economic crisis. The provision of higher education is constantly changing in response to the demands of government, industry, academics and students. Indeed, well before the global financial crisis, business curricula were being influenced by a shift in focus from pure knowledge-based outcomes to more dynamic skills-based outcomes, in order to enable students to apply their knowledge critically and reflectively. The aim has been to develop skills that can be applied in all aspects of students' lives beyond their professional lives in order to meet the expectations of employers. Business graduates should have the capacity to adapt to the shifting knowledge, changed circumstances and sudden upheavals of the business environment. The importance and relevance of graduate skills is now recognised not only by higher education institutions and professional industry bodies, but also by governments and accrediting bodies for quality assurance (Treleaven \& Voola, 2008).

The classifications within university statements of generic skills/graduate attributes emphasise the value of the development and achievement of such skills for an Australian university graduate: core competencies and skills to participate in the workforce; commitment to lifelong learning and renewal; being an active and engaged citizen at both the community and global levels; for a student's own personal, cognitive and affective development.

The articulation of graduate skills in the academic board statements sends a critical message regarding what type of citizens and potential employees the university wants to produce; what knowledge is valued; and how it expects that knowledge to be used for individual, community and national development. It makes an explicit statement about the role of that particular university in the future tense, not just as a teaching, learning and research process, but in the dynamic processes and intersection of community, social, economic and political development. Hager, Holland and Beckett (2002) highlight the educational importance of graduate skills in regard to: course development, as they provide common course outcomes; course delivery and assessment; and provision of quality assurance measures. In addition, graduate skills can promote and enhance students' commitment to lifelong learning (Candy, 1991), and reflective and self-regulated learning (Boekaerts, 1997; Boekaerts \& Cascaller, 2006). In summary, Bowden et al. (2000) suggest that there are three principal arguments for the inclusion of graduate skills in higher education, all of which relate to the shifting role of universities: it is now considered the role of universities to produce citizens, who can be agents for social change and good in the community; upon graduation, students face, and need to be prepared for, an uncertain future; and employers expect to see a certain set of capabilities demonstrated by graduates.

There is thus a need to develop these skills and capabilities in all our graduates, which has led to the reshaping of the business curriculum in many ways. For example, changes have been occurring in what are considered to be the desired outcomes of students' learning; learning and teaching policy and practice; the modes of delivery; and assessment practices. Significantly, graduate skills are also having an impact on the academic standards that higher education institutions are expected to meet as well as the level of academic achievement required of 
students.

This discrepancy, vagueness and overall lack of convergence on the conceptualisation and integration of generic skills can be attributed perhaps - amongst other factors such as the internationalisation of higher education and the broadening of stakeholders involved in the policy process - to the shifting function of universities. Their role has gradually changed from being communities of teaching, learning and research, to one in which emphasis is placed on quality assurance and graduate achievement of sets of skills and capabilities that will allow students to be active participants in the community and workforce, and act as global citizens. Some researchers link "this shift to the emergence of an 'information society'... where greater pressures are placed on professionals ... and workers to both manage and master particular kinds of knowledge." (Star \& Hammer, 2008, pp. 238-9) The development of the concept of generic skills represents a move from the traditional curriculum focus on "content" and knowledge to one which emphasises "process".

This shift in the role of universities has broadened the range of interest groups participating in higher education policy and teaching and learning processes. Pressure for graduate skills is being applied in particular by industry and government bodies, who are concerned about the type of employee and/or citizen that universities are producing: "The continual focus on graduate skills is really part of a bigger, as yet unresolved, debate about the purpose of university education and how to develop educated persons who are both employable and capable of contributing to civil society." (Business Higher Education Round Table, cited in James, Lefoe, \& Hadi, 2004, p. 175)

There is now the added dimension of students who identify themselves as paying customers, leading to increased student expectations regarding teaching quality and learning support, in particular, the growing representation of international students in the cohort - of the 544,000 international students in Australia in 2008, 39\% were enrolled in higher education (Access Economics, 2009). The majority of international students are from China and India, and bring with them the differing expectations and learning needs that must be addressed in not only curricula planning and design, but also teaching and learning pedagogy and research. This takes on particular significance in regard to government policy, which seeks to reward tertiary institutions for high levels of student satisfaction (Illing, 2005).

\section{Research methodology and approach}

\subsection{Project objectives}

The broad objectives for our Graduate Skills project (Vu, Rigby, \& Mather, 2011) were to identify and develop effective strategies and resources to embed and assess graduate skills within undergraduate business programs. We aimed to improve student learning outcomes in the four areas of critical thinking, ethical practice, sustainability and teamwork through the design, development and dissemination of learning and teaching resources targeting these skills. We used findings from previous research, workshops and evaluations for students and staff, and professional knowledge in order to design learning and teaching activities and academic standards (levels of achievement). More specifically, the project aimed to: produce literature reviews concerning the teaching and assessing of graduate skills in business education; develop and test a set of learning modules that embody good practice for promoting teaching and learning of the selected graduate skills; develop a framework for assessing the success of the introduction of graduate skills (learning) at different academic levels; and develop standards for guiding teaching and learning and the assessment of skills development.

\subsection{Project methodology}

Our project was underpinned by an action research methodology (Haggarty \& Postlethwaite, 2003), which involved a cycle of deliberative activity: planning, acting, observing and reflecting. The participative techniques and shared reflective practice within this methodology proved to be effective in approaching a process of renewal and change in learning and teaching. The methodology was also appropriate to the staged nature of the project (see below). The project team received input from students, academics and industry representatives throughout, which significantly shaped the delivery of project activities, such as workshops and the development of learning and teaching resources.

\subsubsection{The team}

The project was a partnership between seven universities delivering business education in Australia. The business programs represented within the team provided a broad cross-section of disciplines and university contexts. All members face similar teaching challenges, including: large class sizes; a significant proportion of international students; a mixture of degree, dual degree and combined degree programs in a variety of sub-disciplines; and professional accreditation standards and compliance requirements. Each member of the 
project team was an Associate Dean responsible for learning and teaching, and were participants in the ABDC T\&L Network. The team represents a community of practice with a shared commitment to embedding graduate skills in the business curriculum and assuring the quality of those skills. Having a range of tertiary institutions involved was critical to the project methodology, since it meant that the team could provide an effective platform to pilot the embedding strategies identified through the course of the project and to enact change in business faculties.

The team worked closely together throughout the project, despite the significant geographical distance between members. We met face-to-face every three months for intensive workshops which were held at rotating team institutions; we also spoke in monthly teleconferences. Responsibilities for tasks were assigned to pairs of team members (the "buddy" system). With the busy schedules of team members, mutual encouragement and feedback was critical to maintaining momentum. This system was also an efficient way to allocate work amongst a large and dispersed group. Team members were directly involved with the design and execution of the workshops and activities, and experienced firsthand the value of graduate skills by working closely with students and academics on the teaching strategies: this approach embodied the concept that engaging with graduate skills should enable transformation for all those involved. The enthusiasm generated from this interactive approach continued to drive progress in the later stages.

\subsubsection{Stage 1A: July - December (Semester 2), 2008}

During the first stage, we defined and refined the detail of the project and its methodology in consultation with the ABDC. A literature search on graduate skills in general and how to assess these was initiated.

\subsubsection{Stage 1B: January - June (Semester 1), 2009}

We defined the specific graduate skills considered to be of primary interest, and then produced a comprehensive literature review about graduate skills in general as well as for the four identified skills (Rigby et al., 2009). Based on the findings, we produced an initial set of learning modules and standards of achievement to measure students' attainment of the graduate skills. These were trialled with 35 students drawn from six Australian states (the seven collaborating institutions) in an intensive three-day residential workshop held at Macquarie University in Sydney, NSW (April 2009). Business students with an average performance of a credit or above, enrolled in second and third-year units from a variety of sub-disciplines (such as accounting, human resources and business management), were invited to apply to participate in the workshop. The credit requirement ensured that these were students who had engaged significantly with the current curriculum and thus were able to reflect adequately on differences in the materials used at the workshop. Team members selected applicants at their respective institutions, with extra considerations about demographic backgrounds, work experience and sub-disciplines taken into account in order to obtain a representative sample of business students.

The workshop featured a welcoming icebreaker activity session, interactive mini-lectures and eight learning modules. Students were tested before and after the workshop on their understanding of the four graduate skills; allocated to teams for collaborative work and presentations; and asked to provide feedback on the materials. Student presentations on the final day were viewed by visiting industry liaison representatives. The workshop was facilitated by the team members, who worked closely with students to investigate ways of enhancing student receptiveness to learning and practising each of the four skill areas. This event formed the basis for the workshop model that we used to trial, disseminate and embed graduate skills across Australian universities for the remainder of the project (see Daly, Leveson, \& Dixon, in this Issue); the locations and participants for these workshops are set out in Table 1.

Business academics were also surveyed about their opinions on both existing and optimal strategies for embedding graduate skills into curricula. Using this data and considering the unique conditions at our own institutions, we then refined the materials and devised strategies for implementation within specific undergraduate business programs in the following semester.

\subsubsection{Stage 2A: July - December 2009 (Semester 2), 2009}

We launched the Graduate Skills project website, www.graduateskills.edu.au, which is the platform for the teaching and learning resource package developed during the project. This is intended as a dynamic and interactive online resources hub; in this spirit we posted and updated drafts of our materials for review and feedback. This web package now contains literature reviews, exemplars, templates, multimedia resources and guides on using, adapting and creating modules, standards and teaching strategies for graduate skills.

The learning modules and standards were also trialled at the seven partner institutions, where students and staff gave feedback on their experience with these materials. Evaluation forms were distributed to participating 
academics and students, and they were asked to rank their level of engagement (using a Likert scale) with the learning modules and the modules' effectiveness in developing their understanding of graduate skills. Evaluation forms are also on the website, and users are encouraged to complete them when downloading the learning modules and standards. Feedback about the learning modules indicates that the majority of students considered that the learning module prompted them to ask questions in class; to discuss the main issues with their peers; to do additional research into the issue presented in the module; and that it improved their understanding of the graduate skills targeted by the module.

We developed academic standards for the four specific graduate skills plus a generic model for standards of achievement, based on pre- and post-testing results of students from the first national workshop in April 2009. Student responses yielded clear distinctions between different levels of understanding of each of the skills and provided the initial framework for the standards. The process itself was particularly useful because it enabled our team to conceptualise each graduate skill in a consistent way (see Wood, Thomas, \& Rigby, in this Issue, on assessment and standards).

A literature review was produced on assessment of graduate skills (Rigby et al., 2010). We also followed up with the students who participated at the April 2009 workshop about the continuing impact of the workshop on their studies; 21 of the 35 original workshop participants were interviewed as a follow-up assessment of its effectiveness. The open-ended questions related to how their understanding and application of graduate skills had improved and developed since the workshop. Their input led to refinement of the learning modules and subsequent workshops in 2009 and 2010. Using the accumulated data, the team continued to refine the materials and develop a revised set of learning modules.

\subsubsection{Stage 2B: January - July (Semester 1), 2010}

During the final stage, the team continued to disseminate materials and strategies and receive feedback on project materials through further workshops for students and academics (see Table 1).

A three-day residential workshop for high-achieving students was held at Macquarie University (July 2010). These students received a high university entrance score and will participate in a "Merit Scholar" program throughout their undergraduate studies at Macquarie University (see Harrison, in this Issue). The program includes an average of 40 scholars each year, the majority from business. This workshop followed the same format as the first national workshop in April 2009.

Another three-day residential workshop for students and academics was held in northern Australia (July 2010), which consisted of parallel sessions involving both students and academics. Staff and students were engaged together in the activities - students doing and learning; academics observing, and reflecting on practice and application. Academics also applied the standards of achievement developed by the team (one standards rubric specific to each skill) to measure the outcomes of student work.

There was also a half-day workshop for academics only, held in Victoria (June 2010). Team members engaged participants in using the learning modules and standards to teach and assess graduate skills in their programs.

More than 150 students and academics drawn from a mix of business discipline areas from 20 Australian universities (see Table 1) participated in trialling and refining the learning and teaching resources in five workshops staged throughout the project. The workshops were used by the team to test and refine learning modules and rubrics, and to facilitate professional development for staff.

Finally, the website was redesigned, and the team wrote guides to using the website and the associated materials. Further modifications were made to the standards; additional learning modules were developed; and the team wrote guides to adapting learning modules and the standards, based on feedback from these workshops and trials in the partner institutions during the previous stage. The team also produced a final report setting out the strategies and outcomes of the project (Vu, Rigby, \& Mather, 2011).

\section{Project outcomes}

\subsection{Method of working}

Our team members benefited from the collaborative and peer-learning aspects of the project, through completing tasks and reviewing each other's work in pairs. The buddy approach worked well as it allowed a large team to concentrate on different tasks and increased the output. The pairings were changed for different tasks during the project. The requirement of the ALTC that projects are collaborations between universities has been an extra benefit as we were able to hold team meetings around Australia; thus we were exposed to a range of policy and practice specific to each partner institution. 


\subsection{Benefits for the team}

A key principle underpinning the concept of "embedding" is that it is not simply a process of information transfer but rather that it involves a degree of transformation in the way that graduate skills are conceived and applied to relevant situations; for example, through case studies, problem solving, debates and class discussion. A critical factor throughout the project, therefore, has been the quality of the interaction between student, teacher and resource materials. The real-time face-to-face demonstration of the value of graduate skills has been particularly effective in changing attitudes, especially for the academics on the team.

\subsection{Benefits for students}

Students were an integral part of our project. We included students as participants from the early stages of the project with the first national workshop in April 2009. The standards and rubrics developed in the project were based on pre- and post-testing with these particular students. Student evaluations of the modules, both at the workshop and in classes during the trials in the team institutions, led to a further cycle of review and refinement of the learning modules.

Student participants responded enthusiastically to the workshops and many later gave presentations to external audiences advocating the benefits of graduate skills, based on their positive experiences. These flow-on student activities represent encouraging and significant outcomes in terms of dissemination and impact. Successful uptake of graduate skills at the undergraduate level relies not just on academic staff developing and adhering to learning and teaching policy and procedure, but also student buy-in of the value of graduate skills. Further workshops involved students, academics and industry, which created further opportunities for professional development in an authentic setting. We often talk about students needing authentic learning activities - well, it works for staff also!

Ultimately, the project has produced positive outcomes for students by developing better ways to embed graduate skills in the curriculum. These strategies will reach students through the significant amount of professional development we have facilitated using authentic resources that we have prepared and tested. We have also disseminated the materials and results widely so the benefits will be spread in Australia and internationally. The standards and rubrics developed should assist in improving outcomes.

\subsection{Benefits for academics}

We have generated stronger and broader engagement with the benefits, challenges and methods of teaching and learning graduate skills in business education. The ability of team members to involve other academics with the issue of graduate skills has been essential. The team members were primarily Associate Deans for teaching and learning in their own institutions, and they were also members of the ABDC T\&L Network. These factors enabled them to generate broad support for using the project's learning and teaching resources, and for effecting general cultural change amongst academics. The project generated the participation of over 80 academics through our workshops and many more through presentations and other forms of dissemination. We have provided them with practical and accessible learning activities and assessment frameworks to use in their classes. The universities' cooperation was particularly valuable in the 2009 spring semester trial of learning modules in a variety of undergraduate business units. Their support was also evident in the strong attendance at project workshops by a range of academics from different institutions. In each workshop, almost every academic indicated they would use or adapt the learning activities and standards in the future; we have also received positive feedback from academics who trialled our learning activities in their classes in the spring semester of 2009.

\section{Future directions}

\subsection{Learning and teaching resources}

The project has made available a range of pedagogical materials that can be used to help students develop a subset of graduate skills, and to assess the extent of their learning. The resources are available on the Graduate Skills website (www.graduateskills.edu.au) and include a wide variety of targeted activities - ranging from research to teaching activities - such as real-world case studies and supplementary reading material; suggested teaching methods and lesson plans; literature reviews identifying best practice; and standards of achievement, which provide a framework to assess the attainment of each skill.

These materials were tested and refined with students and academics through multiple iterations, and can be used, adapted and embedded in an undergraduate business program in order to develop these graduate skills. Through our multi-faceted dissemination activities, we have generated stronger and broader engagement with the benefits, challenges and methods of teaching and learning graduate skills in business education. 
The project has been innovative in investigating the development of these capabilities in a holistic way, rather than as isolated skills. The inclusion of ethical practice and sustainability has shown that the approach can be applied to dispositional development in addition to the learning of more clearly defined skills such as teamwork and critical thinking.

\subsection{Implementation of resources}

The project has stimulated policy change and curriculum development activities at a unit level and, at some team institutions, at a program level. Many of the project learning and teaching resources are being used in undergraduate and postgraduate business, statistics and interdisciplinary units within the seven participating universities, some as a trial initiative and others on a more permanent basis. In particular, the use of the jigsaw method for stakeholder analysis in sustainability and ethical practice in business contexts will be implemented in business departments across Australia (see Wood \& Dixon, and Petocz \& Dixon, in this Issue).

An example of program-level change is the University of Tasmania. Their Bachelor of Business program was substantially reviewed during 2009 to comply with the University's common course structure. In concert with this, the Faculty of Business has been engaged in mapping graduate attributes across major strands of study, and is further considering a substantial change to the common first-year core in the Bachelor of Business program with a view to specific coverage of graduate skills. The Faculty of Business will introduce from 2011 a new compulsory core unit into its Bachelor of Business Program, which will cover communication, teamwork, critical thinking, academic writing, and computer literacy. The unit coordinator intends to make use of some of the resources and assessment rubrics developed by the project.

As a direct outcome of the project, our model was implemented in the form of a discrete, intensive workshop program to enhance the graduate skills of high-achieving students at Macquarie University. As previously mentioned, this program will service students who have received a high university entrance score ("merit scholars"), and it will include an average of 40 scholars each year, the majority from Business. The first merit scholar workshop was held in 2010 as a residential event over three days, and included later year business students from Macquarie University (see Harrison, in this Issue).

Another ALTC-funded project ("Capstone courses in undergraduate business degrees: better course design, better learning activities, better assessment") was initiated in response to concerns similar to ours, as well to a broad lack of understanding about the purpose of capstone courses within undergraduate business degrees, and about the best approaches to course design, learning activities and assessment. It will develop resources to enable universities to improve the design, delivery and assessment of their undergraduate business capstone courses, ultimately enhancing student learning outcomes. The Graduate Skills learning modules, standards and guides will provide a starting point for the project's planned resources on accessible, practical guides regarding the design, learning activities and assessment of capstone courses in business programs. We have included a paper from the Capstone project team (Elizabeth van Acker (lead), Janis Bailey, Lorelle Frazer, Raymond Hibbins, Keithia Wilson) in this special edition (see van Acker \& Bailey).

The project has had direct positive outcomes for over 150 students and academics and has addressed a significant, documented industry need for tested, workable learning materials and standards. The flow-on effects to business education in Australia will benefit a large number of students and academics. The Graduate Skills website (www.graduateskills.edu.au) is a dynamic resource that encourages and supplements the learning and teaching of graduate skills in business education. The website continues to be regularly accessed by visitors from around the world (56 countries as of September 2010). Users can access and adapt practical materials for developing and assessing graduate skills. This will be supported in the future through the ABDC T\&L Network. It is intended that the website will be enriched and maintained to assist with active dissemination of the project outcomes for at least the next three years.

A significant outcome of the project has been the influence on policy. Business academics are more aware now of the need to clearly define graduate skills and communicate how those skills are developed over a degree program. Various tools for curriculum mapping of content and graduate outcomes are being developed and implemented, such as Sedona ${ }^{\circledR}$ (https://sedonaweb.com/) and Re:View ${ }^{\mathcal{O}}$ (http://reviewsecure.com, University of Technology, Sydney). The attention focussed on professional development for academics and for better communication with all stakeholders will assist with reducing the expectations gap between what universities can deliver and what employers want us to deliver.

Business education in Australia has large numbers of students and academics. The professional development needs of academics to support their teaching and assessment of graduate skills as well as their own discipline area is significant. Business teaching is funded at a low rate in Australia so classes are large: this makes 
developing and assessing graduate skills more difficult than for other disciplines.

In a limited way the project addressed how students can be motivated to engage with graduate skills - even a change in terminology from generic to graduate skills can influence the engagement of students. Nevertheless, more needs to be done to motivate students to engage with these skills.

\section{Acknowledgements}

Thank you to the team for the invaluable peer learning that was enabled by the collegial atmosphere throughout the project. We would also like to thank the ALTC and the ABDC for the opportunity to work on this project and to make a difference to business education. Thanks also to Joanna Sabri for her help on this paper and the others in this Special Issue.

\section{References}

Access Economics. (2009). The Australian education sector and the economic contribution of international students. [Online] Available: http://www.accesseconomics.com.au/publicationsreports/showreport.php?id=192 (April 14, 2009).

Australian Society of Certified Practising Accountants \& Institute of Chartered Accountants in Australia. (1997). Joint submission: review of higher education financing and policy. [Online] Available: http://www.dest.gov.au/archive/highered/hereview/submissions/submissions/A/ASCPA_and_ICAA.htm (January 27, 2011).

Barrie, S. C. (2004). A research-based approach to generic graduate attributes policy. Higher Education Research \& Development, 23, 261-75.

Boekaerts, M. (1997). Self-regulated learning: a new concept embraced by researchers, policy-makers, educators, teachers, and students. Learning and Instruction, 7, 161-86.

Boekaerts, M. \& Cascallar, E. (2006). How far have we moved toward the integration of theory and practice in self-regulation? Education Psychology Review, 18, 199-210.

Bowden, J., Hart, G., King, B., Trigwell, K., \& Watts, O. (2000). Generic capabilities of ATN university graduates. [Online] Available: http://www.clt.uts.edu.au/ATN.grad.cap.project.index.html (April 1, 2009).

Business, Industry and Higher Education Collaboration Council (BIHECC). (2007). Graduate employability skills. [Online] Available: http://www.dest.gov.au/NR/rdonlyres/E58EFDBEBA83430EA5412E91BCB59DF1/20214/GraduateEmployabili tySkillsFINALREPORT1.pdf (April 29, 2009).

Candy, P. (1991). Self-direction for lifelong learning. San Francisco: Jossey Bass.

Freeman, M., Hancock, P., Simpson, L., Sykes, C., Petocz, P., Densten, I., \& Gibson, K. (2008). Business as usual. ABDC Scoping Report.

Hager, P., Holland, S., \& Beckett, D. (2002). Enhancing the learning and employability of graduates: the role of generic skills. Business/Higher Education Round Table: B-HERT Position Paper no.9.

Haggarty, L. \& Postlethwaite, K. (2003). Action research: a strategy for teacher change and school development? Oxford Review of Education, 29, 4, 423-448.

Hoban, G., Lefoe, G., James, B., Curtis, S., Kaidonis, M., Hadi, M., Lipu, S., Mcharg, C., \& Collins, R. (2004). A web environment linking university teaching strategies with graduate attributes. [Online] Available: http://jutlp.uow.edu.au/2004_v01_i01/hoban001.html (March 16, 2009).

Illing, D. (2005). Shock teacher ranking for unis. The Australian Higher Education Supplement.

James, B., Lefoe, G., \& Hadi, M. (2004). Working 'through' graduate attributes: a bottom-up approach. In F. Sheehy, \& B. Stauble (Eds.). Transforming knowledge into wisdom: holistic approaches to teaching and learning: Proceedings of the HERDSA 2004 International Conference, Miri, Sarawak. Milperra. NSW: HERDSA.

Kember, D. \& Leung, D. (2005). The influence of active learning experiences on the development of graduate capabilities. Studies in Higher Education, 30, 155-70.

National Centre for Vocational Education Research (NCVER). (2009). Defining generic skills: at a glance. Adelaide: Australian National Training Authority. [Online] Available: http://www.ncver.edu.au/research/proj/nr2102b.pdf (January 27, 2011).

Rigby, B., Wood, L., Clark-Murphy, M., Daly, A., Dixon, P., Kavanagh, M. et al. (2009). Review of graduate 
skills: critical thinking, teamwork, ethical practice and sustainability. [Online] Available: http://www.graduateskills.edu.au/literature-review (January 24, 2010).

Rigby, B., Wood, L., Clark-Murphy, M., Daly, A., Dixon, P., Kavanagh, M., Leveson, L., Petocz, P., \& Thomas, T. (2010). The assessment of graduate skills: orientating students and standards for an uncertain future. [Online] Available: http://www.graduateskills.edu.au/literature-review (August 10, 2010).

Star, C. \& Hammer, S. (2007). Teaching generic skills: eroding the higher purpose of universities, or an opportunity for renewal? Oxford Review of Education, 34, 237-51.

Thompson, D., Treleaven, L., Kamvounias, P., Beem, B., \& Hill, E. (2008). Integrating graduate attributes with assessment criteria in business education: using an online assessment system [Online] Available: http://jutlp.uow.edu.au/2008_v05_i01/3_Thompson011.html (March 3, 2009).

Treleaven, L. \& Voola, R. (2008). Integrating the development of graduate attributes through constructive alignment. Journal of Marketing Education, 20, 160-73.

Vu, T., Rigby, B., \& Mather, G. (2011, in press). Final report: embedding the development and grading of generic skills across the business curriculum. Australian Learning and Teaching Council. [Online] Available: http://www.altc.edu.au/project-embedding-development-grading-macquarie-2008.

Table 1. Participation of students and academics in Graduate Skills workshops

\begin{tabular}{|l|c|c|c|}
\hline Workshops & Students & Academics & Institutions \\
\hline National, April 2009 & 35 & 7 & 7 \\
\hline Victoria, June 2010 & - & 26 & 6 \\
\hline $\begin{array}{l}\text { Northern Australia, July } \\
2010\end{array}$ & 25 & 18 & 13 \\
\hline Sydney, July 2010 & 22 & 22 & 5 \\
\hline $\begin{array}{l}\text { New South Wales, } \\
\text { September 2010 }\end{array}$ & - & & 1 \\
\hline
\end{tabular}

